\title{
Lung Function Impairment and Workplace Control Measures among Marble Stone Carvers in Sa-Kyin Village, Madayar Township, Myanmar
}

\author{
Htun $Z Z Z^{1}$, Win $\mathrm{YY}^{2}$, Myat $\mathrm{AM}^{3}$, Naing $\mathrm{SM}^{2}$
}

${ }^{1}$ Department of Medical Research, Ministry of Health and Sports, Myanmar, ${ }^{2}$ Preventive and Social Medicine Department, University of Medicine, Mandalay, Myanmar, ${ }^{3}$ Occupational and Environmental Department, Ministry of Health and Sports, Myanmar,

\section{ABSTRACT}

Introduction: Marble rocks, composed of dust containing calcium carbonate and silica particles, predispose to a higher prevalence of occupational lung diseases. This study aimed to assess workplace control measures and lung function impairment among marble stone carvers.

Methods: A cross-sectional descriptive study was conducted among 120 marble stone carvers in Sa-Kyin Village, Madayar Township in May 2019. Information about existing control measures in the workplace was assessed using a pre-tested structured questionnaire and participants' lung function using spirometry. Respirable dust measurements in twelve randomly selected workers were performed by personal air sampling pumps.

Results: It was found that $9.2 \%$ of marble stone carvers used disposable or cloth masks throughout the working time, but no one was found using appropriate devices like respirators. No one reported about regular medical checkup and provision of health education at the workplaces. Spirometry testing showed $55.8 \%$ had lung function impairment. Concentrations of respirable dust ranged from 7.19 to $10.13 \mathrm{mg} / \mathrm{m}^{3}$, significantly higher than the recommended Threshold Limit Value $\left(3 \mathrm{mg} / \mathrm{m}^{3}\right)$. In multivariable logistic regression analysis, development of lung function impairment was associated with age [adjusted Odds Ratio $(\mathrm{aOR})=2.84 ; 95 \% \mathrm{Cl}=1.02,7.91$ ] and use of face mask $(\mathrm{aOR}=0.11 ; 95 \% \mathrm{Cl}=0.01,0.91)$.

Conclusion: The working environment was found dusty, and a significant proportion of workers had lung function impairment. It is essential to adopt proper dust control measures in stone carving workplaces. Preventive measures like medical surveillance and health education program are vital to reduce the burdens from occupational lung diseases.

Key words: Lung function test, Marble, Occupational disease

\section{Introduction}

Occupational lung diseases due to exposure to dust are one of the major health hazards. ${ }^{1}$ Occupational dust exposure leads to a greater prevalence of lung function impairment. ${ }^{2}$ Marble rocks are composed of dust containing calcium carbonate and silica particles

DOI: https://doi.org/10.3126/ijosh.v11i1.34972

Date of submission: 15.02.2021

Date of acceptance: 03.04.2021

\section{Corresponding Author}

Dr. Zaw Zaw Htun

M.B.,B.S, MMedSc (Preventive and Tropical Medicine)

Research Officer,

Department of Medical Research,

Ministry of Health and Sports, Myanmar

E-mail: zzawhtoon@gmail.com

ORCID ID - https://orcid.org/0000-0003-1256-8763 that can cause lung diseases, including occupational asthma, chronic obstructive pulmonary disease (COPD), silicosis and cancer. ${ }^{3,4}$

Globally, it is estimated that there are 2.3 million deaths annually due to diseases attributed to the workplace in 2012. ${ }^{5}$ The prevalence of silicosis is extremely high, and more than 5 million people are exposed to respirable silica dust globally. ${ }^{6}$ Approximately $15 \%$ of COPD, $11 \%$ of asthma, and $9 \%$ of cancer were reported worldwide in $2000 .{ }^{7}$ In the UK, the prevalence of occupational COPD was $10 \%$ for males and $11 \%$ for females in 1990, and the prevalence of pneumoconiosis accounted for $9 \%$ of the total number of occupational lung disease in $1997 .{ }^{\circ}$ Eighteen percent of workers in

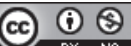

This journal is licensed under a Creative Commons AttributionNon Commercial 4.0 International License. 
Vietnam and $55 \%$ of workers in India engaged in coal mining and quarrying of sedimentary rock have been found to have silicosis. ${ }^{9}$

Lung function assessment using spirometry is an invaluable screening test, which is performed to monitor the effects of occupational/environmental exposures. ${ }^{10}$ The best practice to assess dust exposure is to use the personal sampler, which can estimate the workers' average dust exposure. ${ }^{11}$

Most work processes may cause significant dust exposure, leading to serious health risks if it is not properly planned, controlled, and managed. The health hazard is not entirely linked to occupations but linked to the working environment and improper use of protective measures. ${ }^{11}$ Prevention is vital for decreasing the incidence of morbidity and disability from occupational lung diseases. ${ }^{12}$

Sa-Kyin Village is located in Madayar Township, 21 miles to the north of Mandalay. It has a population of nearly 7,000 living in 1,500 households. More than 60 percent of the households depend on carving statues as an occupation. This study aimed to determine the workplace control measures in the working environment, assess lung function impairment among marble stone carvers, and measure dust concentration in selected workplaces.

\section{Methods}

A cross-sectional descriptive study was carried out in Sa-Kyin Village, Madayar Township, Myanmar during May 2019. Marble stone carvers working in marble stone carving workplaces for more than one-year duration were included. The required sample size $(n=120)$ was calculated at a $95 \%$ confidence interval, with the degree of precision at 0.09 level, which was based on the $64 \%$ prevalence rate of abnormal lung function test among the gold miners in Myanmar in 2016. ${ }^{2}$ There were around 700 marble stone carving workplaces in the Sa-Kyin Village. Among them, 120 workplaces were selected randomly for this study. One marble stone carver was chosen at each workplace by the lottery method for the interview and measuring lung function test.

The data collection tools included a pre-tested structured questionnaire, spirometry, and personal air sampling pump. The questionnaire included sociodemographic and work characteristics and workplace control measures. Content validity of the questionnaire was approved by a specialist from the Occupational and Environmental Health Department and 20 stone carvers with a similar background to the target population were pre-tested before data collection.

\section{Spirometry testing}

Lung function assessment was tested using spirometry (Vitalograph Alpha Touch) supported by the Occupational and Environmental Health Department, Ministry of Health and Sports (MOHS), Myanmar. The procedure was performed by a trained technician from this department and validated by the Occupational Safety and Health Association (OSHA) recommendation. In spirometry testing, FVC (forced vital capacity), FEV1 (forced expiratory volume in one second) and FEV1/FVC ratio were recorded. Lung function was categorized into normal (FEV1/FVC $\geq$ LLN, FEV1 $\geq$ LLN and FVC $\geq$ LLN) and impaired (obstructive pattern - FEV1/FVC < LLN and FEV1 < LLN, restrictive pattern - FEV1/FVC $\geq$ LLN and FVC < LLN)..$^{13}$ The values recommended by OSHA were used as reference values, which were based on spirometry data collected by the NHANES III (National Health and Nutrition Examination Surveys III) published in 1999. Caucasian values for FVC and FEV1 were multiplied by 0.88 to adjust those for Asian workers. ${ }^{14}$

\section{Dust concentration measurement}

A personal air sampling pump was used to measure the respirable dust concentration exposed to the marble stone carvers over 8 hours. Twelve randomly selected marble stone carvers were chosen for measurement. The sampler was attached to the worker's upper chest, not more than $30 \mathrm{~cm}$ away from the nose-mouth region. The instrument used was the air sampling pump (Airchek sampler), supported by the Occupational and Environmental Health Department, MOHS, Myanmar.

\section{Data management and analysis}

Data entry and analysis was done using SPSS Version 25 software. Mean, standard deviation, frequency and percentage were used as descriptive statistics, and Pearson's Chi-square test was used as inferential statistics. Multivariable logistic regression analysis was applied in assessing the predictors of lung function impairment. Variables like socio-demographic and work characteristics and workplace control measures were the independent variables. Those variables whose $p$-value was $\leq 0.25$ in univariate analysis were selected as candidate variables for multivariable analysis. 


\section{Ethical consideration}

This study was reviewed and approved by the Academic and Ethical Board of the University of Medicine, Mandalay, Myanmar. (ID No. 277/UMM/2019)

\section{Results}

In this study, the participants were aged 18 to 51 years, and the mean age was 30.45 years $(S D \pm 9.33)$. Most of the participants (92.5\%) were male and current smokers were $50.8 \%$. Four stone carvers (3.3\%) had a previous history of respiratory diseases, where three had asthma, and the other had tuberculosis. Sociodemographic and work characteristics were described in Table 1.

While assessing the existing control measures in the workplaces, only $9.2 \%$ of marble stone carvers used disposable or cloth masks throughout the working time, but no one was found using appropriate respirators. Seventy percent of workers never used any protective measures to prevent dust exposure, and the reasons were that the use of these makes them feel hot, breathless, and uncomfortable to wear. They also believed that marble dust exposure would not have any severe effects on them. No employer supported the personal protective equipment to the workers in the workplaces. No one reported about regular medical checkup and provision of health education at the workplaces. Out of 120 workplaces, $63.3 \%$ did not use any control measures in the working environment, whereas the remaining applied wet methods, including wet drilling and water spraying onto marble stones' cutting surfaces. There were no workplaces that applied general ventilation and local exhaust ventilation. All marble stone carvers worked outdoors or under the buildings with the roof to cover the sun. Besides, no marble stone carvers joined the Social Security Board, Myanmar for workers' benefits and contributions. Dust concentration had never been checked in the workplaces.

The mean measurement of respirable dust concentration in selected workplaces was $8.78 \mathrm{mg} /$ $\mathrm{m}^{3}(\mathrm{SD} \pm 0.90)$, ranging from 7.19 to $10.13 \mathrm{mg} / \mathrm{m}^{3}$. In lung function testing, $44.2 \%$ of participants showed normal spirometry results, whereas $55.8 \%$ showed the impaired results, with $49.2 \%$ as the restrictive pattern and $6.7 \%$ as the obstructive pattern.

The results of univariate and multivariable logistic regression analyses in assessing the predictors of lung function impairment were shown in Table 2. The variables which are included in the final model were age and use of face masks. Marble stone carvers above 40 years of age were nearly three times more likely to develop lung function impairment than their counterparts $(\mathrm{aOR}=2.84 ; 95 \% \mathrm{Cl}=1.02,7.91)$. Marble stone carvers who did not use face masks were $89 \%$ less likely to have lung function impairment. (aOR = $0.11 ; 95 \% \mathrm{Cl}=0.01,0.91)$.

Table 1: Frequency distribution of socio-demographic and work characteristics among marble stone carvers $(n=120)$

\begin{tabular}{lccc}
\hline Socio-demographic characteristics & Frequency & Percent & P-value \\
\hline Age & & & \\
$<40$ years & 96 & 80.0 & 0.000 \\
$\geq 40$ years & 24 & 20.0 & \\
Sex & 111 & 92.5 & 0.000 \\
Male & 9 & 7.5 & \\
Female & 2 & & 0.000 \\
Education status & 51 & 1.7 & \\
No formal education & 50 & 42.5 & \\
Primary school & 15 & 41.7 & \\
Middle school & 2 & 12.5 & \\
High school & & 1.6 & 0.855 \\
University/Graduate & 59 & & \\
Smoking status & 61 & 49.2 & \\
Non-smokers & & 50.8 & \\
Current smokers & &
\end{tabular}




\begin{tabular}{|c|c|c|c|}
\hline \multicolumn{4}{|c|}{ Underlying respiratory diseases } \\
\hline Yes & 4 & 3.3 & 0.000 \\
\hline No & 116 & 96.7 & \\
\hline \multicolumn{4}{|l|}{ Years of employment } \\
\hline$\leq 5$ years & 37 & 30.8 & 0.031 \\
\hline $6-10$ years & 30 & 25.0 & \\
\hline$>10$ years & 53 & 44.2 & \\
\hline \multicolumn{4}{|l|}{ Working hours } \\
\hline$<8$ hours & 53 & 44.2 & 0.235 \\
\hline$\geq 8$ hours & 67 & 55.8 & \\
\hline \multicolumn{4}{|l|}{ Size of work } \\
\hline Small ( $\leq 5$ workers) & 37 & 30.8 & 0.622 \\
\hline Medium (6-10 workers) & 38 & 31.7 & \\
\hline Large (>10 workers) & 45 & 37.5 & \\
\hline
\end{tabular}

Table 2: Results of univariate and multivariable logistic regression analyses in assessing the predictors of lung function impairment $(n=120)$

\begin{tabular}{|c|c|c|c|c|c|c|}
\hline \multirow[b]{2}{*}{ Potential predictors } & \multicolumn{2}{|c|}{ Lung Function Impairment } & \multirow[b]{2}{*}{ Crude OR } & \multirow[b]{2}{*}{$95 \% \mathrm{Cl}$} & \multirow[b]{2}{*}{$\begin{array}{l}\text { Adjusted } \\
\text { OR }\end{array}$} & \multirow[b]{2}{*}{$95 \% \mathrm{Cl}$} \\
\hline & $\begin{array}{c}\text { Present } \\
\text { N }(\%)\end{array}$ & $\begin{array}{c}\text { Absent } \\
\text { N (\%) }\end{array}$ & & & & \\
\hline \multicolumn{7}{|l|}{ Age } \\
\hline$<40$ years & $49(51.0)$ & $47(49.0)$ & Ref & \multicolumn{3}{|c|}{ Ref } \\
\hline$\geq 40$ years & $18(75.0)$ & $6(25.0)$ & 2.87 & $1.05-7.88$ & $2.84^{*}$ & $1.02-7.91$ \\
\hline \multicolumn{7}{|l|}{ Sex } \\
\hline Female & $5(55.6)$ & $4(44.4)$ & Ref & & \multirow{2}{*}{ NA } & \\
\hline Male & $62(55.9)$ & $49(44.1)$ & 1.01 & $0.26-3.97$ & & \\
\hline \multicolumn{7}{|l|}{ Education status } \\
\hline High & $12(70.6)$ & $5(29.4)$ & Ref & & \multirow{2}{*}{ NA } & \\
\hline Low & $55(53.4)$ & $48(46.6)$ & 0.48 & $0.16-1.45$ & & \\
\hline \multicolumn{7}{|l|}{ Smoking status } \\
\hline Non-smoker & $36(61.0)$ & $23(39.0)$ & Ref & & \multirow{2}{*}{ NA } & \\
\hline Current smoker & $31(50.8)$ & $30(49.2)$ & 0.66 & $0.32-1.36$ & & \\
\hline \multicolumn{7}{|c|}{ Underlying respiratory diseases } \\
\hline No & $64(55.2)$ & $52(44.8)$ & Ref & & \multirow{2}{*}{ NA } & \\
\hline Yes & $3(75.0)$ & $1(25.0)$ & 2.44 & $0.25-24.13$ & & \\
\hline \multicolumn{7}{|l|}{ Year of employment } \\
\hline$\leq 5$ years & $18(48.6)$ & $19(51.4)$ & Ref & & \multirow{2}{*}{ NA } & \\
\hline$>5$ years & $49(59.0)$ & $34(41.0)$ & 1.52 & $0.69-3.32$ & & \\
\hline \multicolumn{7}{|l|}{ Working hour } \\
\hline$<8$ hours & $28(52.8)$ & $25(47.2)$ & Ref & & \multirow{2}{*}{ NA } & \\
\hline$\geq 8$ hours & $39(58.2)$ & $28(41.8)$ & 1.24 & $0.60-2.56$ & & \\
\hline \multicolumn{7}{|l|}{ Size of work } \\
\hline Small & $23(62.2)$ & $14(37.8)$ & Ref & & \multirow{2}{*}{ NA } & \\
\hline Others & $44(53.0)$ & $39(47.0)$ & 0.69 & $0.31-1.52$ & & \\
\hline \multicolumn{7}{|l|}{ Use of face masks } \\
\hline Use & $10(90.0)$ & $1(9.1)$ & Ref & \multicolumn{3}{|c|}{ Ref } \\
\hline Not use & $57(52.3)$ & $52(47.7)$ & 0.11 & $0.01-0.89$ & $0.11^{*}$ & $0.01-0.91$ \\
\hline \multicolumn{7}{|l|}{ Dust control measures } \\
\hline Present & $21(47.7)$ & $23(52.3)$ & Ref & & \multirow{2}{*}{ NA } & \\
\hline Absent & $46(60.5)$ & $30(39.5)$ & 1.68 & $0.79-3.55$ & & \\
\hline
\end{tabular}

${ }^{*}$ p-value $<0.05$ 


\section{Discussion}

A cross-sectional descriptive study was carried out to assess workplace control measures and lung function impairment among marble stone carvers in Sa-Kyin Village, Madayar Township, Myanmar. One hundred and twenty marble stone carvers were included in this study.

Concerning the use of personal protective measures (face masks or respirators), only $9.2 \%$ used them always throughout the working time. They used ordinary cloth masks or disposable surgical masks, but no one used proper protective devices like respirators. In a previous study in a cement factory of the United Arab Emirates, nearly a quarter claimed to use masks all the time even though personal protective equipment were available for all factory workers. ${ }^{15}$ Likewise, a study among marble cutting workers reporting the use of personal protective measures was only $5 \%$. However, after intervention measures and health education sessions two times, their use among workers rose from $5 \%$ to $57.8 \%$. Therefore, this study strongly suggested performing interventions such as health education and training sessions to increase the use of preventive measures effectively among the workers in dusty jobs. ${ }^{3}$

A total of twelve respirable dust measurements were performed, and the concentration ranged from 7.19 to $10.13 \mathrm{mg} / \mathrm{m}^{3}$. All the measurements exceeded the recommended Threshold Limit Value (TLV) based on the American Conference of Governmental Industrial Hygienists $(\mathrm{ACGIH})$ for low toxicity, $3 \mathrm{mg} / \mathrm{m}^{3}$. Based on this finding, the study site's working environment is dusty and hazardous for the workers. The mean concentration of respirable dust in cement production in Iran was $11.9 \mathrm{mg} / \mathrm{m}^{3}$ ( $\left.\mathrm{SD} \pm 14.7\right)$, which was also higher than the recommended TLV. ${ }^{16}$ However, 22 measurements were performed in the Greek cement production, and they were below the TLV established in Greece. ${ }^{17}$ Generally, the dust concentration level in the working environment depends on the types of dust control measures adopted in the workplaces. Therefore, it can be concluded that there were still weaknesses in the dust control measures in the study site so that it would be necessary for the authorities to enforce the monitoring and regulations in the workplaces.

Spirometry results showed lung function impairment in $55.8 \%$ of marble stone carvers. The prevalence of restrictive pattern was about eight times higher than that of the obstructive pattern. In the early study conducted in gold mines, two-thirds of the workers had lung function impairment, and the restrictive pattern was more prevalent than the obstructive pattern. ${ }^{2}$ This result is supported by a previous study conducted among Libyan quarry industry workers, reporting lung function parameters were significantly lower in the exposed group of occupational dust. ${ }^{18}$

The majority of marble stone carvers who use face masks were found to have lung function impairment. In multivariable logistic regression analysis, the workers who do not use face masks were less likely to develop lung function impairment than their counterparts (aOR $=0.11,95 \% \mathrm{Cl}=0.01-0.91$ ). Likewise, a previous study conducted in gold mines reported similar findings. ${ }^{2}$ The reasons for these were only disposable masks or ordinary cloth masks were used among workers instead of appropriate devices like respirators and the disposal of dust-covered disposable masks may act as a source of re-exposure to the workers, which predisposes to the occurrence of lung function impairment. Therefore, the use of appropriate respirators should be encouraged, which can be done by health education, awareness-raising, and appropriate training programs in the workplaces. This suggestion is similar to a study conducted among cement factory workers in the United Arab Emirates, mentioning the workers who use the proper respiratory protection devices (N95 particulate respirator masks) all the time had a lower prevalence rate of respiratory impairment. ${ }^{15}$

There was no statistically significant association between years of employment and lung function impairment, although the proportion of presence of impairment was higher in the group with more serviced years. The comparable results were found in the study conducted among workers in the gold mines ${ }^{2}$ and the Libyan quarry industry. ${ }^{18}$ However, lung function parameters were significantly decreased with length of employment years in the study among quarry workers of stone crushing industrial site in Nigeria. ${ }^{1}$ Some reasons can explain the discrepancy results. The occurrence of lung function impairment may not solely depend on the duration of employment years. This may also be related to factors such as individual susceptibility and amount of exposure or dose of dust entering the body.

In this study, the screening test using spirometry was used to assess the lung function impairment among the workers. It was necessary to use further tests such as chest X-ray to provide a definite diagnosis of the 
impairment. It is expected that the results of the study would highlight the respiratory problems and help the workers raise awareness of these problems. It is also expected that the regulatory authorities would make appropriate control and preventive measures to reduce the occupational disease burdens among workers in dusty conditions.

\section{Conclusion}

The working environment was found dusty, and a significant proportion of marble stone carvers had lung

\section{References}

1. Nwibo AN, Ugwuja El, Nwambeke NO, Emelumadu OF, Ogbonnaya LU. Pulmonary Problems among Quarry Workers of Stone Crushing Industrial Site at Umuoghara, Ebonyi State, Nigeria. Int J Occup Environ Med. 2012 Oct;3(4):178-85.

2. Kay KA. Factors Affecting Respiratory Impairments among Drill Workers in Small-scale Gold Mines at Sint-Ku Township in Mandalay, Myanmar. [Thailand]: Burapha University; 2016.

3. Shrivastava A, Tomar SP, Patel M. Prevalence of Symptoms of Occupational Lung Diseases in Marble Cutting Workers. Int J Community Med Public Health. 2018 Jul 23;5(8):3368.

4. Beckett WS. Occupational Respiratory Diseases. N Engl J Med. 2000;8. Available from: https://pubmed. ncbi.nlm.nih.gov/10666432/

5. Takala J, Hämäläinen $P$, Saarela $K L$, Yun $L Y$, Manickam K, Jin TW, et al. Global Estimates of the Burden of Injury and IIIness at Work in 2012. J Occup Environ Hyg. 2014 May 4;11(5):326-37.

6. Sen S, Mitra R, Mukherjee S, K. Das P, Moitra S. Silicosis in Current Scenario: A Review of Literature. Curr Respir Med Rev. 2016 Mar 3;12(1):56-64.

7. Nelson DI, Concha-Barrientos M, Driscoll T, Steenland K, Fingerhut M, Punnett L, et al. The Global Burden of Selected Occupational Diseases and Injury Risks: Methodology and Summary. Am J Ind Med. 2005 Dec 1;48(6):400-18.

8. Karadzinska J. Occupational Lung Diseases as a Public Health Problem. In: Silicosis in Current Scenario: A Review of Literature [Internet]. 2005. Available from: https://www.researchgate.net/ publication/284205189_Silicosis_in_Current_ Scenario_A_Review_of_Literature function impairment. The findings indicated that it is essential to adopt proper dust control measures such as the wet method, spraying water onto the marble stone cutting surface, in stone carving workplaces to reduce emissions and exposure to the workers. Health education programs should prioritize among workers, including sharing information about the occupational hazards and diseases and proper use and maintenance of personal protective equipment. Medical surveillance should be done before the workers are employed and repeated at regular intervals.

9. WHO. Fact Sheet No 238: Silicosis [Internet]. 2000 [cited 2019 Feb 18]. Available from: http://www.nzdl.org/ gsdlmod?e=d-00000-00---off-0cdl--00-0----0-10-0---0--0direct-10---4-------0-1|--11-en-50---20-about---00-0-100-0--4----0-0-11-10-0utfZz-8-00\&cl=CL1.242\&d=HAS Hf58c7c472d6ca58330314f.2\&x=1

10. Moore VC. Spirometry: Step by Step. Breathe. 2012 Mar 1;8(3):232-40.

11. WHO. WHO | Hazard Prevention and Control in the Work Environment: Airborne Dust [Internet]. World Health Organization Geneva; 1999 [cited 2019 Feb 17]. Available from: https://www.who.int/occupational_ health/publications/airdust/en/

12. Boschetto P, Quintavalle S, Miotto D, Cascio NL, Zeni E, Mapp CE. Chronic Obstructive Pulmonary Disease and Occupational Exposure. J Occup Med Toxicol. 2006;6.

13. Townsend MC. Spirometry in the Occupational Health Setting. J Occup Environ Med. 2011 May;53(5):569-84.

14. OSHA. Spirometry Testing in Occupational Health Programs: Best Practices for Healthcare Professionals. 2013;62.

15. Ahmed HO, AbdullahAA. Dust Exposure and Respiratory Symptoms among Cement Factory Workers in the United Arab Emirates. Ind Health. 2012;50(3):214-22.

16. Kakooei H, Gholami A, Ghasemkhani M, Hosseini M, Panahi D, Pouryaghoub G. Dust Exposure and Respiratory Health Effects in Cement Production. Acta Med Iran. 2012;50(2):122-6.

17. Rachiotis G, Kostikas K, Pinotsi D, Hadjichristodoulou C, Drivas S. Prevalence of Lung Function Impairment among Greek Cement Production Workers: A Crosssectional Study. Ind Health. 2018;56(1):49-52.

18. Draid MM, Ben-Elhaj KM, Ali AM, Schmid KK, Gibbs SG. Lung Function Impact from Working in the PreRevolution Libyan Quarry Industry. Int J Environ Res Public Health. 2015 May;12(5):5006-12. 